\title{
ANÁLISE DO PÓLEN ENCONTRADO EM AMOSTRAS DE MEL DE Apis mellifera L. (HYMENOPTERA, APIDAE) EM UMA ÁREA DE SAVANA DE RORAIMA, BRASIL
}

\author{
Sílvio José Reis da SILVA', Maria Lúcia ABSY²
}

RESUMO - Foram analisadas amostras de mel de um apiário localizado na Aldeia do Contão, Roraima, Brasil. As amostras foram obtidas das colheitas nos meses de outubro e dezembro de 1996 e janeiro, fevereiro e março de 1997. Foram identificados um total de 20 tipos polínicos distribuídos em 18 gêneros e 13 famílias. As familias: Mimosaceae (4 espécies), Anacardiaceae (3 espécies), Sterculiaceae ( 2 espécies), Caesalpiniaceae ( 2 espécies) e Amaranthaceae ( 2 espécies) foram as mais representadas, as demais por uma única espécie. Os tipos polinicos mais freqüentes foram: Mimosa polydactyla H.B.K (outubro e dezembro de 1996), Curatella americana L. (janeiro, fevereiro e março de 1997). Encontrou-se três correlações significativas entre as freqüências dos tipos polínicos de: Curatella americana L. X Mimosa polydactyla H.B.K $(\mathrm{r}=-0,99)$, Curatella americana $\mathrm{L} . \mathrm{X}$ Astronium sp $(\mathrm{r}=0,95)$ e Mimosa polydactyla H.B.K e Astronium $\mathrm{sp}(\mathrm{r}=-0,91)$

Palavras-chave: Apis mellifera, pólen, mel, palinologia

Analyses of Pollen Found in Honey Samples of Apis mellifera L. (Hymenoptera, Apidae) in a Savanna Area in Roraima, Brazil

ABSTRACT - Honey samples of one apiary located in Contão village, north of Roraima State, Brazil were analyzed. The samples originated from crops of October and December, 1996 and January, February and March, 1997. A total of 20 pollen types were identified; they were distributed among 18 genera and 13 families. The families: Mimosaceae (4 species), Anacardiaceae ( 3 species), Sterculiaceae ( 2 species), Caesalpiniaceae (2 species) and Amaranthaceae (2 species) were the most represented. The other families were represented by a single species. The most frequent pollen types were: Mimosa polydactyla (October and December, 1996) and Curatella americana (January, February and March, 1997). Three significant correlations among the frequencies of pollen types were found; Curatella americana L. X Mimosa polydactyla G.B.K. (r $=-0,99)$, Curatella americana L. X Astronium sp $(\mathrm{r}=0,95)$ e Mimosa polydactyla H.B.K e Astronium sp $(\mathrm{r}=-0,91)$.

Key-words: Apis mellifera, pollen, honey, palynology

\section{INTRODUÇÃO}

As abelhas ao visitarem as flores em busca do néctar há a possibilidade de seus pêlos corporais ficarem impregnados com pólen. Embora, na maioria das vezes, o pólen seja transportado para a colméia nas corbículas das abelhas, alguns grãos de pólen de flores visitadas pelas abelhas para a coleta do néctar poderão ser encontrados no mel (Crane, 1985). Este fato permite a determinação da origem floral do mel através da análise do pólen contido nele.

A determinação da origem floral do mel por meio da análise polínica já vem sendo realizada por vários

\footnotetext{
' Museu Integrado de Roraima. Av. Brigadeiro Eduardo Gomes s/n - Parque Anauá CEP 69.305010 Boa Vista - RR, Brasil. Tel. (0XX95)6231733 - silviorr@mandic.com.br

${ }^{2}$ Instituto Nacional de Pesquisas da Amazônia - INPA. Av. André Araújo 1756-69011-970 Manaus -AM, Brasil. Tel. (0XX92)643-3110 luciabsy@inpa.gov.br
} 
pesquisadores no Brasil, destacando-se entre os pioneiros os trabalhos de Braga (1961) e Santos (1961).

Na Amazônia, Carreira et al. (1986), Carreira \& Jardim (1994) e Oliveira et al. (1998) utilizaram a análise polínica do mel como meio para determinar as fontes de néctar de Apis mellifera $\mathrm{L}$.

Absy et al. (1980) determinaram as plantas produtoras de néctar através da análise polínica do próprio néctar contido na vesícula melífera de Melipona seminigra Cock e Melipona rufiventris paraensis Ducke.

Em Roraima, estudos para determinar a origem floral do mel foram realizados por Silva \& Rebouças (1996; 1998).

\section{MATERIAL E MÉTODOS}

A aldeia do Contão está situada ao nordeste do estado de Roraima $\left(3^{\circ}\right.$ $27^{\prime} \mathrm{N}$ e $60^{\circ} 26^{\prime} \mathrm{W}$.). A vegetação é do tipo savana (Radambrasil, 1975). As áreas abertas apresentam um tapete graminoso formado principalmente por espécies de Andropogon sp., Trachypogon $s p$, recortado por árvores de características xeromórficas como Byrsonima sp., Curatella americana L. e Bowdichia sp. entre outras. Ocorrem buritizais (Mauritia flexuosa L.), acompanhando os pequenos cursos de água. Nas margens do rio Cotingo, ocorrem matas ciliares com predominância de espécies de leguminosas de porte arbóreo e arbustivo, espécies de Combretaceae, Anacardiaceae e Rubiaceae.

As amostras de mel foram obtidas das colheitas efetuadas em todo o apiário da Aldeia do Contão nos meses de outubro de 1996 a março de 1997. De cada colheita foi separada uma amostra de $500 \mathrm{ml}$ de mel.As amostras foram preparadas segundo o método da acetólise de Erdtman (1960). De cada amostra foram montadas três lâminas dos sedimentos de mel usando-se nas montagens a gelatina glicerinada (SalgadoLabouriau, 1973). Em seguida foi feita a lutagem com parafina.

A identificação dos tipos polínicos foi realizada por comparação com o pólen das espécies vegetais coletadas na área de estudo e por meio de literatura especializada (SalgadoLabouriau, 1973; Absy, 1975; 1979; Ybert, 1979; Barth, 1989; 1990; 1996).

Os tipos polínicos foram analisados qualitativamente e quantitativamente, sendo classificados, de acordo com o percentual de ocorrência mensal, baseando-se em Maurizio \& Louveaux (1965), como: pólen dominante, freqüência acima de $45 \%$; pólen acessório, freqüência de $15 \%$ a $45 \%$; pólen isolado, freqüência menor que $15 \%$.

Foram analisadas nove amostras de mel, sendo duas do mês de outubro, três de dezembro, duas de janeiro, uma de fevereiro e uma de março. No mês de novembro não houve colheita de mel. Nos casos de mais de uma amostra por mês, foi calculada a média aritmética mensal da freqüência dos tipos polínicos encontrados. De cada amostra foram contados um 
mínimo de 1000 grãos de pólen.

\section{RESULTADOS E DISCUSSÃO}

Em amostras de mel é comum a observação dos grãos de pólen sem o uso de tratamento químico por meio do método de Maurizio \& Louveaux (1965). Usando-se esse método ocorreram dificuldades em separar os grãos de pólen dos outros sedimentos contidos no mel. Os sedimentos de mel foram, então, preparados pelo método da acetólise (Erdtman, 1960).

A quantidade de grãos de pólen, para apenas uma fração da amostra, foi muito pequena e muitas lâminas não continham um mínimo de 1000 grãos de pólen. As amostras então foram enriquecidas, em quantidade de grãos de pólen, com o aumento do tempo de centrifugação e realizandose sucessivas centrifugações para uma mesma amostra.

\section{Tipos polínicos encontrados}

Foram identificados um total de 20 tipos polínicos distribuídos em 18 gêneros e 13 famílias. A família Mimosaceae foi representada por quatro espécies, Anacardiaceae por três espécies, Sterculiaceae por duas espécies, Caesalpiniaceae por duas espécies e Amaranthaceae por duas espécies, as demais estavam representadas por uma única espécie.

Foram identificados oito tipos polínicos até o nivel de espécie, onze até o nível de gênero e um a nível de família tipo, e, em cada amostra, um pequeno percentual ficou indeterminado.
A identificação de espécies por meio da análise polínica, é bastante dificultada, em alguns gêneros, devido a grande semelhança entre os grãos de pólen dessas espécies. Considerando este fato e comparando os resultados obtidos na análise polínica com as observações de campo, podemos supor que no gênero Eichhornia (Fig. 1.1) pode ter ocorrido o pólen de Eichhornia heterosperma Alex, Eichhornia diversifolia Solms. e Eichhornia sp. Em Acacia (Fig. 1.2A) pode ter ocorrido o pólen de Acacia lorentensis Macbr e Acacia polyphylla DC. Em Melochia (Fig. 1.3) pode ter ocorrido o pólen de Melochia parvifolia H.B.K. e Melochia villosa Fawc. \& Rend. Em Waltheria (Fig. 1.4) pode ter ocorrido o pólen de $W$. americana L. e $W$. vicosissima St. Hill, em Psidium pode ter ocorrido o pólen de Psidium guajava L. e Psidium guianensis SW. Desta forma, o número de espécies pode se elevar para um total de 25 .

A classificação dos tipos polínicos encontrados em amostras de mel conforme suas freqüências está na tabela 1.

O pólen de Mimosa polidactyla H.B.K (Figs. 1.5 e 1.6)apareceu como pólen dominante nos meses de outubro e dezembro de 1996 e como pólen acessório em dezembro, janeiro, fevereiro e março de 1997.

O pólen de Curatella americana L. (Figs. 1.2 e 1.6) apareceu como dominante em janeiro, fevereiro e março de 1997 e como pólen acessório em dezembro de 1996. 

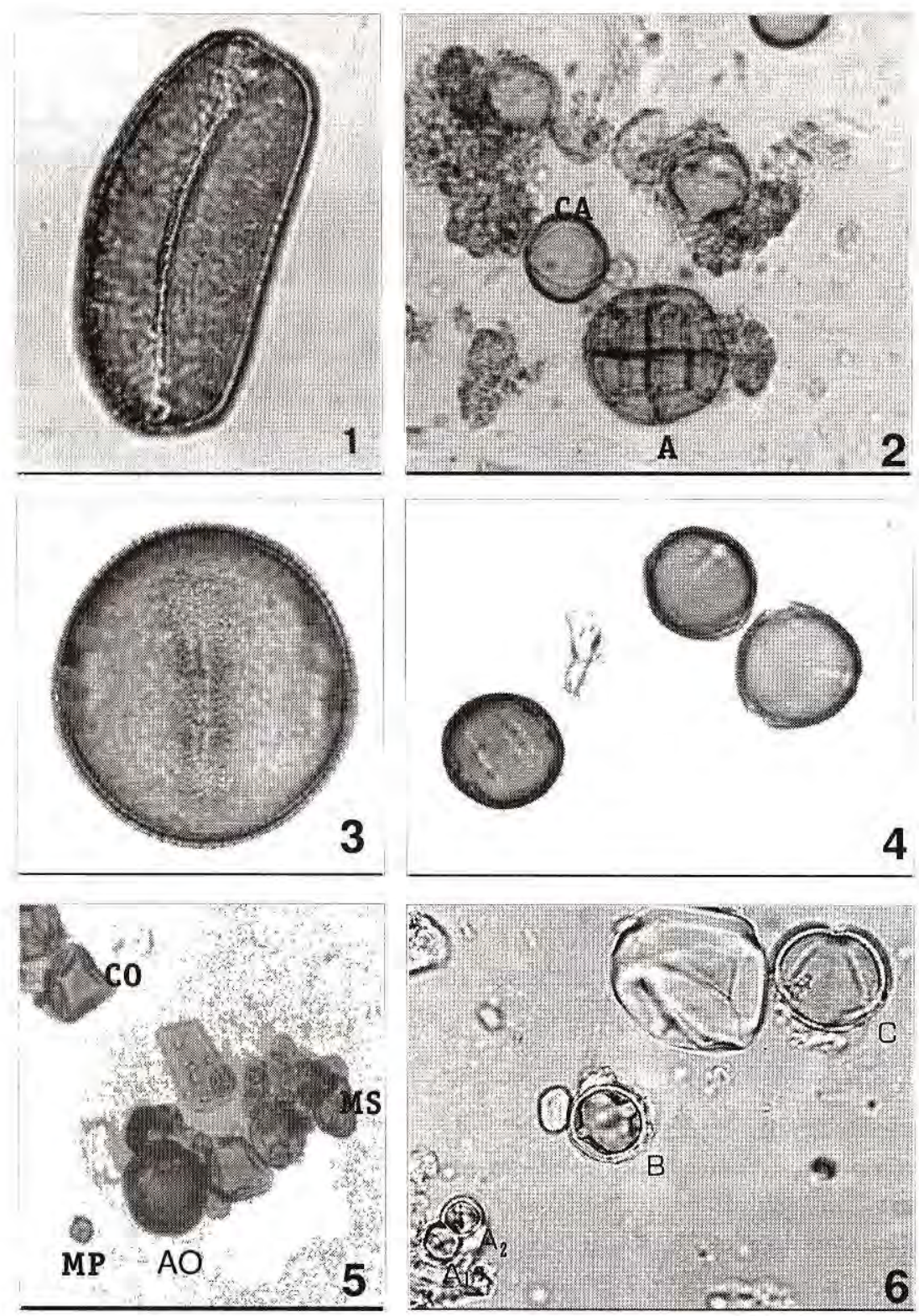

Figura 1. Fotomicrografias de grãos de pólen encontrados em amostras de mel da Aldeia do Contão, Roraima, Brasil. 1. Eychhornia sp. (Pontederiaceae) $1000 \mathrm{x} ; 2$. (A) Acacia sp. (Mimosaceae) 400x ; 2. (CA) Curatella americana L. (Dilleniaceae) 1000x.; 3. Melochia sp. (Sterculiaceae) $1000 \mathrm{x} ; 4$. Waltheria americana L, (Sterculiaceae) 400x; 5. (CO) Copaifera officinalis L. (Caesalpiniaceae); 5. (MP) Mimosa polidactylla H.B.K e, 5. (MS) Mimosa somnians H.B.K. (Mimosaceae); 5. (AO) Anacardium occidentali L. (Anacardiaceae) 400x; 6. $\left(\mathrm{A}_{1}, \mathrm{~A}_{2}\right)$ Mimosa polidactylla H.B.K. (Mimosaceae); 6. (B) Byrsonima sp. (Malphigiaceae). 6. (C) Curatella americana L. (Dilleniaceae) $1000 \mathrm{x}$ 
Tabela 1. Freqüência percentual dos tipos polínicos encontrados em amostras de mel nos meses de outubro/1996 e dezembro, janeiro, fevereiro e março/1997 na Aldeia do Contão, Roraima. Freqüências seguidas da letra "d" para pólen dominante, "a" para pólen acessório e demais como pólen isolado.

\begin{tabular}{|c|c|c|c|c|c|c|}
\hline FAMLIA & ESPÉCIE & $\begin{array}{l}\text { OUT. } \\
(\%)\end{array}$ & $\begin{array}{c}\text { DEZ. } \\
(\%)\end{array}$ & $\begin{array}{l}\text { JAN. } \\
(\%)\end{array}$ & $\begin{array}{l}\text { FEV. } \\
(\%)\end{array}$ & $\begin{array}{c}\text { MAR. } \\
(\%)\end{array}$ \\
\hline MIMOSACEAE & Mimosa polydactyla H.B.K. & $90.65 d$ & $63.98 \mathrm{~d}$ & $15.98 \mathrm{a}$ & $31.12 \mathrm{a}$ & $22.39 a$ \\
\hline DILLENACEAE & Curatella americana $\mathrm{L}$. & 1.57 & $22.15 a$ & $71.94 \mathrm{~d}$ & $54.45 d$ & $58.23 d$ \\
\hline MALPIGHACEAE & Byrsonima sp. & 1.86 & 10.09 & 4.76 & 7.78 & 0.62 \\
\hline ANACARDACEAE & Astronium sp. & 0.00 & 0.44 & 5.86 & 3.09 & 3.19 \\
\hline CAESALPINACEAE & Copaifera officinalis $\mathrm{L}$. & 4.01 & 0.26 & 0.09 & 0.84 & 0.80 \\
\hline CECROPACEAE & Cecropia sp. & 0.00 & 0.89 & 0.38 & 1.22 & 4.87 \\
\hline MIMOSACEAE & Mimosa somnians H.B.K. & 0.17 & 1,20 & 0.19 & 0.00 & 0.88 \\
\hline MIMOSACEAE & Piptadenia peregrina Benth. & 0.00 & 0.00 & 0.00 & 0.00 & 3.19 \\
\hline COMBRETAGEAE & Combretum sp. & 0.25 & 0.09 & 0.14 & 0.00 & 0.80 \\
\hline MYRTACEAE & Psidium sp. & 0.00 & 0.12 & 0.14 & 0.28 & 0.80 \\
\hline MIMOSACEAE & Acacia sp. & 0.65 & 0.00 & 0.05 & 0.09 & 0.00 \\
\hline ANACARDACEAE & Spondias lutea L. & 0.00 & 0.00 & 0.05 & 0.09 & 0.44 \\
\hline PONTEDERACEAE & Eichhomea sp. & 0.27 & 0.03 & 0.00 & 0.00 & 0.00 \\
\hline STERCULACEAE & Waltheria sp. & 0.05 & 0.06 & 0.05 & 0.00 & 0.18 \\
\hline STERCULACEAE & Melochia sp. & 0.00 & 0.03 & 0.04 & 0.09 & 0.09 \\
\hline AMARANTHACEAE & Althernantera sp. & 0.00 & 0.00 & 0.00 & 0.00 & 0.27 \\
\hline ANACARDACEAE & Anacardium occidentale L. & 0.00 & 0.00 & 0.00 & 0.00 & 0.27 \\
\hline PASSIFLORACEAE & Passiffora sp. & 0.00 & 0.00 & 0,00 & 0.00 & 0.27 \\
\hline CAESALPINACEAE & Bauhinia ungulata L. & 0.04 & 0.03 & 0.00 & 0.09 & 0.00 \\
\hline \multirow[t]{3}{*}{ CARYOPHYLLACEAE } & tipo & 0.00 & 0.00 & 0.00 & 0.00 & 0.09 \\
\hline & indeterminado & 0.47 & 0.63 & 0.33 & 0.84 & 2.65 \\
\hline & espécies visitadas & 10 & 13 & 13 & 11 & 17 \\
\hline
\end{tabular}


Esta classificação da freqüência dos tipos polínicos encontrados em amostras de mel, nem sempre representa as porcentagens de contribuição com néctar de cada espécie. Zander \& Maurizio (1975) apud Barth (1989), consideram méis puros sub-representados em pólen os méis de Robinia, Salvia, Tilia e Medicago quando ocorrerem no espectro polínico de $20-30 \%$ e de Citrus e Lavandula nas freqüências de $10-20 \%$.

É possivel considerar uma amostra de mel como originária de Mimosa, apenas se o pólen tiver freqüência superior a $98 \%$ (Barth, 1989). Neste trabalho, Mimosa polydactyla H.B.K. atingiu a máxima freqüência de $92,24 \%$, no mês de outubro, e nas observações de campo foi procurada exclusivamente para pólen. Em amostras de méis do município de Belém no Pará, Carreira et al. (1986) encontraram o pólen de Mimosa pudica L. com uma freqüência de $78,0 \%$. Carreira \& Jardim (1994) encontraram uma freqüência acima de $80 \%$ de pólen de Mimosa pudica L. nos municípios de Afuá e Peixe-boi, no estado do Pará. Em muitos estudos de interações entre abelhas e plantas, as Leguminosas predominam. Amaral (1953) realizou estudos especificos de leguminosas como plantas apícolas no Parque da Escola Superior de Agricultura "Luiz de Queiroz" e áreas anexas, encontrando 41 espécies visitadas por Apis mellifera L., das quais 4 pertenciam ao gênero Mimosa.

O pólen das espécies: Eichhornia sp., Acacia sp., Melochia sp., Waltheria sp. e que foram procuradas para coleta de néctar por vários meses, ocorreram em uma freqüência média muito baixa, $(0.16 \%$, $0.05 \%, \quad 0.07 \%$ e $\quad 0.06 \%$ respectivamente). O pólen de outras espécies como: Nymphoides sp., Ludwigia sp., Paulinia biocarpa Griseb e Oxalis frutescens L. em que vimos as abelhas coletarem néctar em suas flores, não ocorreram nas amostras de mel.

Os grãos de pólen produzidos por espécies poliníferas tendem a ser menores e de dispersão pelo vento (polinização anemófila), enquanto que os grãos de pólen de espécies nectariferas tendem a ser maiores e terem dispersão por animais (polinização zoófila, Barth, 1985).

A ocorrência de pólen de Cecropia nas amostras de mel vem a confirmar que as espécies essencialmente poliniferas podem estar bem representadas nos espectros polínicos de mel pois, Cecropia sp. fornece pólen que é dispersado pelo vento (pólen anemófilo) e sua presença na área da Aldeia do Contão é baixa. A presença de pólen de Cecropia em amostras de mel é citada por outros autores (Dutra \& Barth, 1997; Barth, 1989). No Municipio de JiParaná - Rondônia, em estudos realizados por Marques-Souza et al. (1993), Apis mellifera L. coletou pólen de Cecropia intensamente em 22 
meses, sendo que nos meses de julho, outubro e novembro de 1987 e novembro e dezembro de 1988, essa espécie ocorreu como pólen dominante. Analisando o pólen coletado por Apis mellifera L. em uma plantação de cacau na Costa Rica, Erickson Júnior et al. (1988) encontraram grãos de pólen de Monocotiledôneas (Gramineae e Palmae) com freqüência superior a $56 \%$ em todas as colméias do estudo.

De um modo geral, os grãos de pólen menores tiveram freqüências mais altas do que os grãos de pólen maiores. Embora a correlação entre "diâmetro do pólen $\mathrm{X}$ freqüência" não tenha sido significativa. Observando a Figura 2 percebe-se esta tendência.
As freqüências de Mimosa polydactyla H.B.K. e Curatella americana $\mathrm{L}$. foram as mais altas entre todas as amostras, médias de $44,82 \%$ e $41,67 \%$ respectivamente para todo o período. Essas duas espécies são poliníferas, fornecendo grande quantidade de pólen. A ocorrência no mel (Figs. 1.5 e 1.6) é normal já que o pólen de espécies poliniferas tende a ser super representado em amostras de mel (Barth, 1989).

Em cada uma das amostras, essas duas espécies juntas somaram mais de $80 \%$ dos tipos polínicos encontrados, o que demonstra a importância apícola das mesmas. É notável a alta correlação negativa $(\mathrm{r}=$

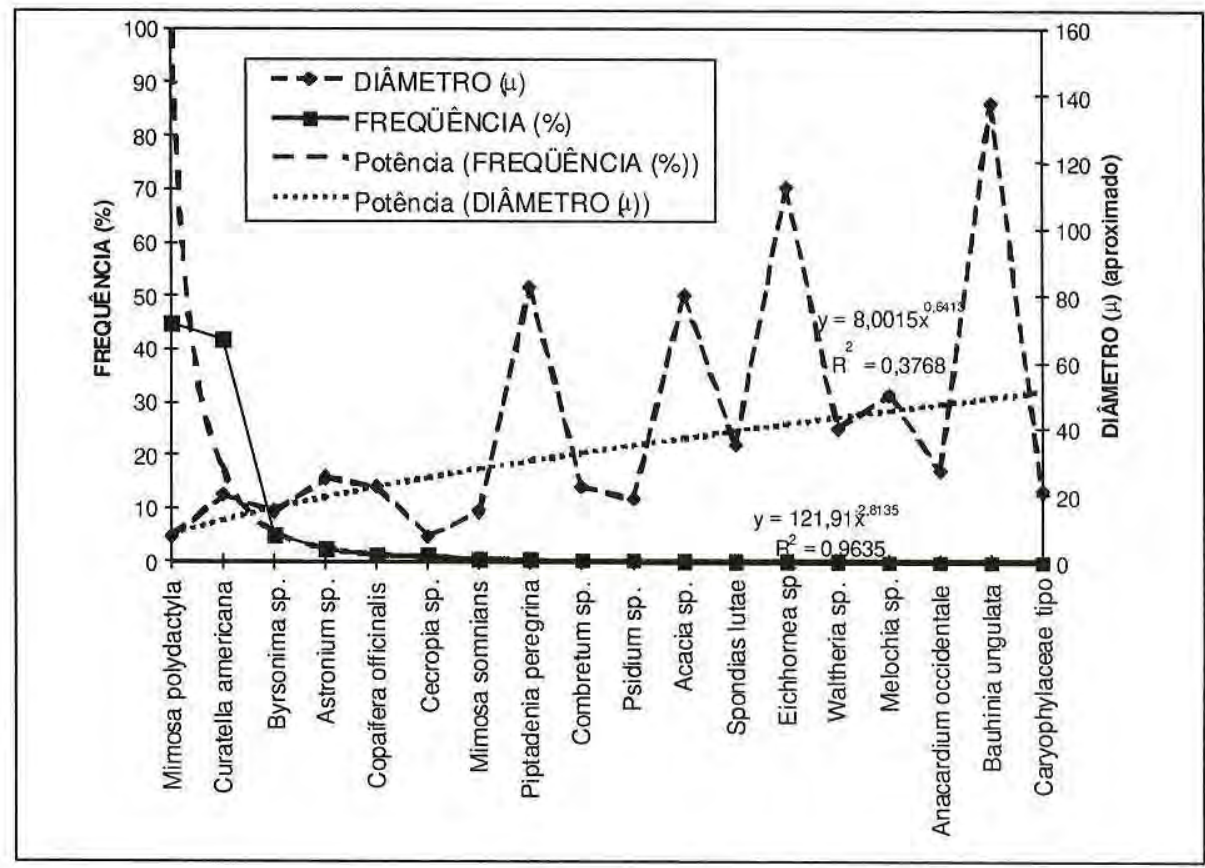

Figura 2. Freqüência média, para todo o periodo, dos tipos polínicos encontrados nos sedimentos de mel, com os respectivos diâmetro e linhas de tendência. 
-0.99 significativa ao nivel de $1 \%$ ) entre as freqüências dessas duas espécies (Tab. 2).

O pólen de plantas poliníferas é considerado "contaminante" em amostras de mel, e sendo assim, suas freqüências não deveriam mostrar um padrão correlato de variação (Fig. 3)

É provável que essas duas espécies desempenhem um papel nutricional importante, e algum fator fez com que as abelhas se alternassem no uso desses recursos alimentares.

A alternância na atividade de coleta entre Curatella americana L. e Mimosa polydactyla H.B.K. podem estar relacionadas com a precipitação, e não somente com a existência de flores na planta. Em períodos de boa umidade no solo, Mimosa polydactyla H.B.K. estava com flores e Apis mellifera $\mathrm{L}$. coletou pólen desta espécie com mais intensidade. Em períodos mais secos, quando as flores de Mimosa polydactyla H.B.K. diminuíam em qualidade e em quantidade de alimento ofertado, Apis mellifera passava a coletar pólen em Curatella americana L. que sendo melhor adaptada ao clima e aos solos das savanas, apresentou indivíduos com flores com oferta de alimento em quantidade e qualidade mais constantes, mesmo em periodos de baixa umidade. Entretanto, a correlação entre a freqüência dessas espécies com a precipitação não foi significativa.

Também foram significativas as correlações entre Astronium sp. e Mimosa polydactyla H.B.K. ( $\mathrm{r}=-0.91) \mathrm{e}$ entre Astronium sp. e Curatella americana L. $(r=0.95)$. A correlação negativa entre Mimosa polydactyla H.B.K e Astronium sp., pode estar indicando preferência pela segunda espécie, em uma relação similar aquela encontrada entre Mimosa polydactyla H.B.K. e Curatella americana L.

Tabela 2. Valores de " $r$ " para correlação entre os sete tipos polinicos com maior freqüência média para todo o período. Outubro/1996 e dezembro a março/1997.

\begin{tabular}{lccccccc}
\hline \multicolumn{1}{c}{ ESPÉCIE } & M.p. & C.a. & By. & As. & C.o. & Ce. & M.s. \\
\hline Mimosa polydactyla & - & & & & & & \\
Curatella americana & $-0,99^{*}$ & - & & & & & \\
Byrsonima sp. & 0,04 & $-0,04$ & - & & & & \\
Astronium sp. & $-0,91^{\star}$ & $0,95^{*}$ & $-0,13$ & - & & \\
Copaifera officinalis & 0,77 & $-0,75$ & $-0,49$ & $-0,61$ & - & \\
Cecropia sp. & $-0,49$ & 0,40 & $-0,44$ & 0,18 & $-0,29$ & - & \\
Mimosa somnians & 0,08 & $-0,16$ & 0,19 & $-0,34$ & $-0,36$ & 0,46 & - \\
\hline
\end{tabular}

* Significativo ao nivel de $1 \%$ de probabilidade 
A correlação positiva entre Astronium sp. e Curatella americana demonstra que, em certos períodos, as abelhas utilizaram essas duas fontes ao mesmo tempo significando uma certa similaridade, como recurso trófico, dessas duas espécies.

\section{CONCLUSÕES}

As amostras de mel de Apis mellifera L. na Aldeia do Contão apresentaram principalmente pólen de Mimosa polydactyla H.B.K. e Curatella americana L., que são espécies preponderantemente poliniferas.

As espécies de Acacia spp., Melochia spp. e Waltheria spp., que são nectariferas e que foram observadas sendo visitadas pelas abelhas para coleta de néctar, podem ter contribuído de forma expressiva na produção de mel.

A determinação da origem floral do mel silvestre, por meio da análise polínica, deve ser bastante criteriosa uma vez que o pólen de espécies nectariferas apresenta baixa freqüência e algumas espécies nem aparecem nos sedimentos de mel.

\section{AGRADECIMENTOS}

Ao Dr. Antônio Carlos Marques Souza e M.Sc. Francisco Plácido Magalhães Oliveira pelas sugestões apresentadas ao trabalho.

A Empresa Brasileira de Pesquisa Agropecuária - CPAF Roraima que permitiu a utilização do laboratório de entomologia onde foram montadas as lâminas dos sedimentos de mel.

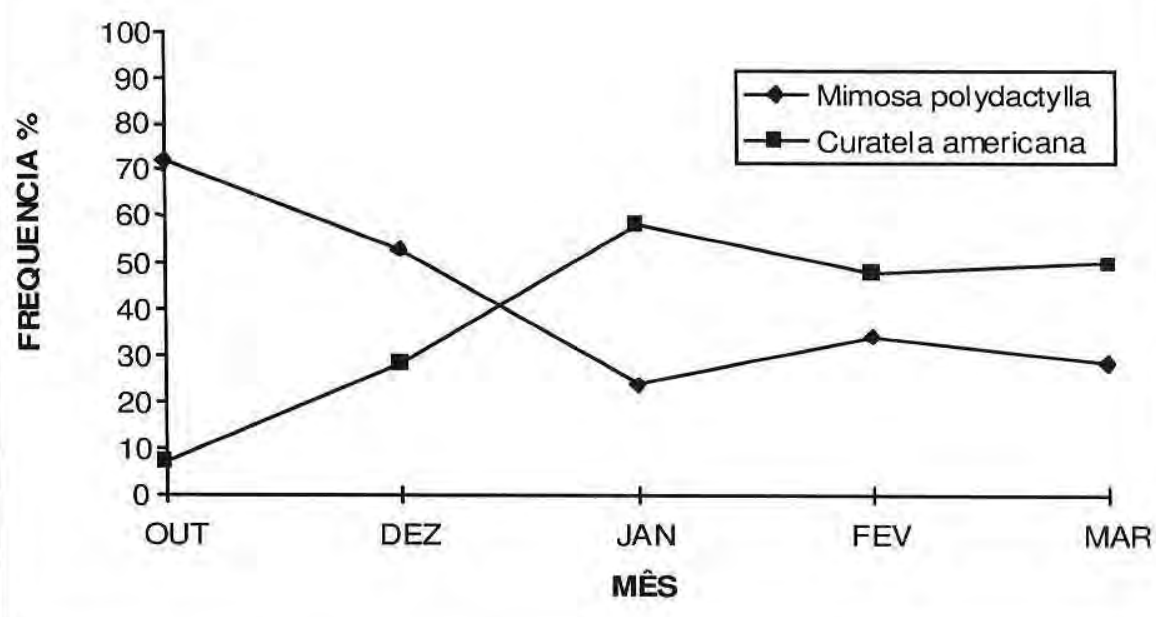

Figura 3. Freqüência média mensal de Mimosa polydactyla H.B.K. e Curatella americana L. em sedimentos de mel de outubro/1996, janeiro/fevereiro/março/1997 (Obs. No mês de novembro os dados foram extrapolados) 


\section{Bibliografia citada}

Absy, M.L. 1975. Polem e esporos do quaternário de Santos (Brasil). Hoehnea. 5:1-26.

Absy, M.L. 1979. A palynological study of holocene sediments in the Amazon Basin. $\mathrm{Ph}$. D. Thesis. Univ. de Amsterdam. Amsterdam, 86p.

Absy, M.L.; Bezerra, E.B.; Kerr, W.E. 1980. Plantas nectariferas utilizadas por duas espécies de Melipona da Amazônia. Acta Amazonica, 10(2):271-281.

Amaral E. 1953. Estudos apicolas em leguminosas, $\mathrm{Ph}$. D. Thesis, ESALQ-USP, São Paulo. 60p.

Barth, F. G. 1985. Insects and flowers: The biology of a partnerships. Princeton University Press. Princeton, New Jersey. $297 \mathrm{p}$.

Barth, O.M. 1989. O pólen no mel brasileiro. Luxor, Rio de Janeiro. 150p.

Barth, O.M. 1990. Pollen in monofloral honey from Brazil. Journal of Apicultural Research, 29(2):89-94.

Barth, O.M. 1996. Monofloral and wild flower honey pollen spectra in Brasil. Ciência e Cultura, 48(3):163-165.

Braga, R. 1961. Flora apícola de Curitiba. Boletim Botânica, 2:1-11.

Carreira, L.M.M.; Jardim, M.A.G. 1994. Análise polínica dos méis de alguns municípios do Estado do Pará - II. Bol. Mus, Para. Emilio Goeldi, sér. Bot. 10(1):83-89.

Carreira, L.M.M.; Jardim, M.A.G.; Moura, C.O.; Pontes, M.A.; Marques, R.V. 1986. Análise polinica nos méis de alguns municipios do Estado do Pará. Simpósio do Trópico Úmido, EMBRAPA/CPATU. 79-84p.

Crane, E. 1985. O livro do mel. 2a. Edição. Nobel. São Paulo. 226 p.

Dutra, V.M.L.; Barth, M.O. 1997. Análise palinológica de amostras de mel da região de Bananal (SP/RJ), Brasil. Geociências, 2(n. especial):174-183.

Erdtman, G. 1960. The acetolysis method: - a revised description. Sv. Bot. Tidskr., 54(4):561-564.

Erickson Júnior, E.H.; Young, A. M.; Erickson, B.J. 1988. Pollen collection by honeybees (Hymenoptera: Apidae) in a Costa Rica cacao (Theobroma cacao) plantation. Journal of Apicultural Research. 27(3):190-196.

Marques-Souza, A.C.; Absy, M.L.; Condè, P.A.A.; Coelho, H.A.1993. Dados da obtenção de pólen por operárias de Apis mellifera no município de Ji-Paraná (RO), Brasil. Acta Amazonica, 23(1):56-76.

Maurizio, A.; Louveaux, J. 1965. Pollen de plantes melliferes d'Europe. U. G. A. F., Paris. 148p.

Oliveira, F.P.M., Carreira, L.M., Jardim, M.A.G. 1998. Caracterização polínica do mel de Apis mellifera L. em área de floresta secundária no município de Igarapé-Açu Pará. Bol. Mus. Para. Emilio Goeldi, Série Botânica, 14(2):157-176

Radambrasil. 1975. Levantamento de recursos naturais. v. 8. MME/Departamento Nacional de Produção Mineral. Rio de Janeiro, 428p.

Salgado-Labouriau, M. L. 1973. Contribuição a palinologia dos cerrados. Acad. Bras. de Ciên., Rio de Janeiro, 291p.

Santos, C.F. de O. 1961. Principais tipos de pólen encontrados em algumas amostras de mel. Revista de Agricultura, 36(2):93-96.

Silva, S.J.R.; Rebouças, M.A.P. 1996. Plantas meliferas do Estado de Roraima. In: Anais do II Encontro Sobre Abelhas. Ribeirão Preto/SP, 2:291.

Silva, S.J.R.; Rebouças, M.A.P. 1998. Plantas melíferas de Roraima - Parte II Bol. Mus. Integrado de Roraima, 4(único):31-38.

Ybert, J. P. 1979. Atlas de pollen de Côte D'ivoire. ORSTOM, Paris. 249p. 